\title{
Correction to: Demographic variables predicting ISIS and Al-Queda armed political violence
}

\author{
Othman Alkhadher ${ }^{1}$ (D) Nicholas C. Scull ${ }^{2}$ \\ Published online: 20 March 2019 \\ (C) Springer Nature B.V. 2019
}

\section{Correction to: Crime Law Soc Change https://doi.org/10.1007/s10611-018-9808-5}

In the original publication, the word Daesh should have been Al-Queda. The word Daesh appeared in the article title, in the first sentence of the abstract, and in the last sentence of the third paragraph of the Introduction section.

Publisher's note Springer Nature remains neutral with regard to jurisdictional claims in published maps and institutional affiliations.

The online version of the original article can be found at https://doi.org/10.1007/s10611-018-9808-5

Othman Alkhadher

prof.alkhadher@ku.edu.kw

Nicholas C. Scull

nscull@gmail.com

1 Psychology Department, Faculty of Social Sciences, Kuwait University, P.O. Box 68168, Keifan, Kuwait

2 General Education, College of Arts and Sciences, American University of Kuwait, P.O. Box 3323, 13034 Safat, Kuwait 